\title{
Improving the Prognosis of Healthcare in the United States
}

\author{
Alison P. Galvani, $\mathrm{PhD}^{1}{ }^{1}{ }^{*}$, Alyssa S. Parpia, $\mathrm{MPH}^{1}$, Eric M. Foster ${ }^{1}$, Burton H. Singer, $\mathrm{PhD}^{2}$, \\ Meagan C. Fitzpatrick, $\mathrm{PhD}^{1,3}$ \\ ${ }^{1}$ Center for Infectious Disease Modeling and Analysis (CIDMA), Yale School of Public Health, 135 \\ College St., Suite 200, New Haven, CT 06510 \\ Emerging Pathogens Institute, University of Florida, P.O. Box 100009, Gainesville, FL 32610 \\ ${ }^{3}$ Center for Vaccine Development and Global Health, University of Maryland School of Medicine, \\ 685 W Baltimore St, Baltimore, MD 21201
}

\section{Abstract}

\begin{abstract}
Although healthcare expenditure per capita is higher for the United States than any other country, over 37 million Americans are entirely without health insurance and 41 million more have inadequate access to care. Whereas ongoing efforts to repeal the Affordable Care Act would exacerbate healthcare inequities, a universal system, such as that proposed in the Medicare for All Act (MAA), has the potential to transform the availability and efficiency of American healthcare. Taking into account both the costs of coverage expansion as well as savings that would be achieved through the MAA, we calculate that a single-payer, universal healthcare system is likely to lead to a $13 \%$ savings in national healthcare expenditure, equivalent to over $\$ 450$ billion annually. The entire system could be funded with less financial outlay than is currently incurred by employers and households through healthcare premiums, as well as existing government allocations. This shift to single-payer healthcare would provide the greatest relief to lower-income households. Furthermore, we estimate that ensuring healthcare access for all Americans would save over 68,000 lives and 1.73 million life-years every year.
\end{abstract}

\section{Introduction}

Over 78 million Americans do not have adequate health insurance, ${ }^{1-3}$ and millions more are at risk of losing coverage. The $24 \%$ of Americans lacking adequate insurance include individuals who are entirely uninsured as well as those for whom out-of-pocket costs and deductibles are disproportionately high relative to their incomes. ${ }^{1}$ Compounding this crisis, over 70 congressional bills have been introduced which aim to undermine the improvements in healthcare access that have been realized by the Affordable Care Act (ACA). The move to repeal the ACA by the current Administration will further jeopardize the healthcare of 21 million Americans. ${ }^{4}$ Despite higher national healthcare expenditure than any other country, constituting $18 \%$ of GDP, ${ }^{5,6}$ the US ranks below 30 countries for many public

*corresponding author: alison.galvani@yale.edu.

Author Contributions:

APG conceived of the study. APG, MCF, ASP \& BS contributed to the writing. ASP \& MCF conducted literature research. MCF,

APG \& ASP conducted the calculations. EF, ASP \& MCF programmed the interface with input from APG. 
health indicators, including preventable deaths, ${ }^{7}$ infant survival, ${ }^{8}$ maternal mortality, ${ }^{9}$ and overall life expectancy. ${ }^{10}$ To address this disconnect, Senator Bernie Sanders introduced the Medicare for All Act (MAA) which proposes a single-payer system of universal healthcare for every American. ${ }^{11,12}$ Here we project both the economic and life-saving impacts likely to be generated by the MAA relative to the current American system. We find that the expected savings from a universal, single-payer system would more than compensate for the increased expenditure associated with universal coverage. Furthermore, universal healthcare would save lives while simultaneously improving the quality and productivity of those lives, as we detail below. Specifically, we calculate that the MAA would reduce national healthcare expenditure by over US $\$ 458$ billion (2017), corresponding to $13.1 \%$ of current expenditure. We also project that the MAA would save more than 68,500 lives every year, compared to the ACA. If the ACA were to be repealed, we would expect an additional annual loss of over 38,500 lives compared to status quo. Compared to healthcare access prior to the enactment of the ACA, MAA would therefore save 107,000 lives annually. To inform the ongoing deliberations of policymakers, we also introduce an interactive online tool through which users can explore how input assumptions influence spending projections and tailor a plan to finance the predicted expenditure. ${ }^{13}$

\section{Budgetary projections for single-payer universal healthcare}

Single-payer universal healthcare has long been perceived as politically and economically impractical for the US. However, Medicare stands as a 54-year real-world test for the viability of single-payer, government-funded healthcare. Since Medicare was established to remedy the widespread refusal of the private sector to cover the elderly, it has significantly and cost-effectively improved the health of previously uninsured recipients. ${ }^{14-16}$ Public opinion is clear: the vast majority of Americans view Medicare as an important program that works well. ${ }^{17}$ If Medicare can succeed in the country's most expensive age cohort, it is reasonable to expect that extending coverage to all Americans would only be more feasible and less costly per-capita.

Previous estimates of the national cost of healthcare under MAA range from a $16.9 \%$ increase to a $27 \%$ decrease. ${ }^{18-24}$ In this study, we estimate the national healthcare expenditure under the single-payer universal system detailed in the MAA. Further, we considered the robustness of our budgetary projections to variation in the values of key parameters that underlie healthcare system costs. As highlighted by the divergent conclusions of the prior MAA evaluations, these inputs can vary as a result of differing expert opinions or empirical uncertainties. Accordingly, we developed the Single-payer Healthcare Interactive Financing Tool (SHIFT; http://shift.cidma.us/) in which these parameters can be adjusted (Figure 1). SHIFT similarly enables the customization of a national financing plan in which insurance premiums paid by employers and individuals would be replaced with options such as a payroll tax. Projections from SHIFT indicate that the MAA would yield net savings for the healthcare system across a wide range of assumptions regarding insurance expansion, service improvements, administrative efficiency, and pharmaceutical pricing (Figure 2). 


\section{Reduced fees for hospital and clinical services}

The first set of savings could be achieved by applying the current Medicare fee schedule across all hospital and clinical services. Hospital and clinical services constitute over a third of healthcare expenditures in the US. ${ }^{29}$ Fees charged to private insurers are often inconsistent and incommensurate with the quality of services. ${ }^{30,31}$ As an example, charges for an uncomplicated vaginal birth vary 10 -fold across California, and less than a third of this variation is attributable to location or the patient population. ${ }^{32}$ Moreover, hospital fees do not correlate with maternal or neonatal outcomes. ${ }^{33}$ The incongruity is even more pronounced when clinical outcomes and costs in the US are compared with those in other countries. The average cost of giving birth in Spain is $\$ 2333$ compared to $\$ 14,910$ in the US, yet the rate of neonatal mortality in the US is double that in Spain. ${ }^{34-36}$ Similarly, appendectomy fees in the US vary from $\$ 9,332$ to $\$ 33,250$, with an inverse correlation to clinical outcomes. For instance, while California has the highest median cost of appendectomies, it also has higher rates of associated morbidity and perforation than other states. ${ }^{37}$ By contrast, Medicare reimburses hospitals and physicians for services at fixed rates. Applying the fees negotiated by Medicare across care for all individuals (Appendix), ${ }^{38-40}$ we calculated that hospital fees would be reduced by $5.54 \%$ and clinical services by $7.38 \%$, amounting to annual savings of $\$ 100$ billion.

From the perspective of healthcare providers, lower per-service fees would be offset by savings from reduced billing and administrative tasks. These activities currently represent a $\$ 768$ billion burden for providers. It has been estimated that consolidation of billing into a unified system has the potential to reduce this expenditure by $\$ 284$ billion, ${ }^{26}$ which would be more than double the proposed change in fees. Another benefit to providers from a single-payer billing system is the elimination of unpaid bills, which exceed $\$ 35$ billion annually for hospitals alone. ${ }^{41}$ Furthermore, overwhelming paperwork is a primary factor in physician burnout. ${ }^{42,43}$ As providers reduce their administrative workload, they free time for patient care, which will bolster career satisfaction ${ }^{42}$ as well as increase their revenue. From the system perspective, the additional provider time will be in demand following the expected increase in utilization, as detailed below.

Recognizing the benefits to providers as well as patients, National Nurses United and Physicians for a National Health Program have both advocated in support of the MAA. By contrast, the American Hospital Association is opposed to the MAA. The AHA has argued that it relies on private patients to subsidize the care of Medicare and Medicaid patients. However, the lower Medicaid fees will be replaced by the relatively higher Medicare reimbursements, and the burden of unpaid bills will be eliminated. This would particularly ameliorate the financial struggles of hospitals serving low-income communities. Furthermore, the financial relief from reduced administrative tasks and eliminated unpaid bills may not yet be routinely considered by stakeholders.

\section{Unified system for billing and administration}

Overhead comprises $12.4 \%$ of spending under private insurance compared with $2.2 \%$ under Medicare. ${ }^{26}$ While there is an inherent risk that such efficiency would not scale, 
it is arguable that expanding current Medicare systems to a larger population would facilitate improved efficiency. Therefore, applying the current overhead rate, we calculate that a further $\$ 225$ billion could be saved annually by consolidating all insurance into the Medicare framework. One component of this drop is the elimination of redundant corporate architecture. A corollary is the truncation of the top-heavy salary architecture of health insurance corporations. The salary for the head of this single-payer system would be capped at the $\$ 210,700$ salary of the Secretary of Health and Human Services. This cap would eliminate the excessive compensation of health insurance company executives, some of whom earn over $\$ 20$ million annually. ${ }^{44}$ In addition to savings on overhead, a comprehensive database of healthcare charges would facilitate detection of fraud, which extracts $\$ 85.7$ billion every year. ${ }^{45}$ Following the transition to a single-payer system in Taiwan, an $8 \%$ reduction in overall national expenditure was attributed to reduction in fraud. ${ }^{27,46}$ In moving from a fragmented healthcare payment system, such as currently exists in the US, to a unified system, irregularities in provider claims can be more easily detected. ${ }^{27}$ For example, excessive claims for physician time may currently be spread across patients with several different insurance providers. However, acknowledging that improvements have been made in fraud detection since Taiwan's transition, we conservatively assume that the improved fraud detection would garner savings amounting to half of what was observed in Taiwan, corresponding to $4 \%$ of total healthcare expenditure. ${ }^{27,46}$ Furthermore, sensitivity analysis examining the contribution of variation in this parameter demonstrated that a transition to MAA would remain cost-saving even without savings from improved fraud detection (Fig 2C).

\section{Pharmaceutical price negotiation}

Currently, $\$ 469$ billion is spent on pharmaceuticals, ${ }^{40}$ fueled by prices which are higher than in any other country and which continue to rise more steeply than inflation. ${ }^{34,47}$ For example, a vial of insulin costs approximately $\$ 300$ in the US ${ }^{48}$ compared to $\$ 30$ in Canada. ${ }^{49}$ Legislation prohibiting price negotiations for pharmaceuticals, supplies, or equipment has hamstrung the current Medicare system. The imperative for price regulation is rivaled by the goliathan political power of pharmaceutical corporations, emboldened by the "Citizens United" Supreme Court decision that lifted restrictions on corporate political expenditures. By contrast, negotiating authority is a fundamental component of the MAA. Through representation of the entire US market, the Department of Health and Human Services would have considerable negotiating power. As a potential model for the federal single-payer system, the US Department of Veterans Affairs (VA) does have the capacity to negotiate for prices that align with the therapeutic value of pharmaceutical drugs. This bargaining power results in pharmaceutical prices that are $40 \%$ lower in the VA system than under Medicare. ${ }^{25}$ Permitting negotiations for pharmaceutical prices with a formulary similar to that used by the VA would boost savings by over $\$ 180$ billion, which we apply for our base case. These annual savings are similar to those proposed through alternative mechanisms for pharmaceutical price reductions by Senator Elizabeth Warren. ${ }^{24}$

Concerns have been expressed that reduced profits for pharmaceutical corporations would dampen biomedical innovation. ${ }^{50}$ However, the observed decline in scientific investment ${ }^{51}$ which has accompanied consistently sizable profit margins for the pharmaceutical industry 
52 suggests that the market assumptions underlying these concerns may be imperfect. Nonetheless, given that optimal or achievable prices might be different from those negotiated by the VA, our interactive tool allows the price reduction to vary from 0 to $60 \%$. Even if pharmaceutical prices remained unaffected, the MAA would still reduce overall healthcare system costs (Figure 2).

\section{Expansion of coverage and services}

The provision of universal healthcare would entail expanded utilization of health services by those who are currently uninsured and those who are insured but for whom cost, such as copays, nonetheless imposes a barrier to healthcare. Empirically, the 38 million Americans who are uninsured tend to forego necessary treatments and prophylactic measures. ${ }^{2}$ Specifically, individuals without any insurance utilize healthcare at $50.1 \%$ of the rate of adequately insured individuals. ${ }^{39}$ There are also 41 million underinsured Americans who have insurance plans with prohibitively high deductibles and/or copays. ${ }^{1}$ Underinsured individuals utilize healthcare at $86 \%$ of the rate of adequately insured individuals. ${ }^{53} \mathrm{In}$ our base case, we assumed that healthcare utilization by both uninsured and underinsured individuals would rise to the level of adequately insured individuals for whom cost does not discourage healthcare utilization. A prior analysis assumed that uninsured individuals have opted not to pay for health insurance because they are in less need of it, ${ }^{23}$ as is empirically supported by the disproportionately high number of younger people who are uninsured. ${ }^{54}$ However, other studies have indicated that uninsured patients may be more likely to have undiagnosed comorbidities and conditions 55,56 that may require increase healthcare resources as compared to insured patients.

\section{The bottom line of Medicare for All}

Through the mechanisms detailed above, we predict that a single-payer healthcare system would require $\$ 3.034$ trillion annually (Figure 3, Appendix), $\$ 458$ billion less than current national healthcare expenditure..$^{40}$ Even after accounting for the increased costs of coverage expansion, our data-driven base case includes $\$ 210$ billion savings on hospital care, $\$ 111$ billion on physician and clinical services, $\$ 224$ billion on overhead, and $\$ 180$ billion on prescription drugs (Figure 3). Consequently, per-capita annual expenditure would drop from $\$ 10,739^{6}$ to $\$ 9,330$, equivalent to a $13.1 \%$ reduction. The expectation of savings is robust to variation in the input parameters. For example, if overhead rates only dropped to $6 \%$ of total health expenditure - rather than Medicare's current $2.2 \%$ - the MAA would still reduce costs by $10.3 \%$. Conversely, savings would increase beyond our base case if our model overestimates the unfulfilled demand among the currently uninsured and underinsured. Given that $\$ 2261$ is already allocated to healthcare by existing governmental and philanthropic sources (Appendix), a further $\$ 773$ billion must be collected by the government to fully fund the MAA. 


\section{Restructuring healthcare expenditure by employers, individuals, and as a nation}

The recent elimination of federal subsidies and the ensuing decline in ACA enrollment have driven a rise of insurance premiums for everyone, including those with employer-sponsored plans. This financial strain could be eased by the savings that arise from a single-payer healthcare system. One proposed financing option would involve a replacement of employer and household insurance premiums with payroll and income taxes, respectively. ${ }^{28}$ Rates would be set such that savings accrue in both cases (Table 1, Appendix). The redirection of premiums to taxes would also be tantamount to a transfer of capital from private holdings to the public sector, with redistributive economic impacts.

Employer contributions to health insurance currently average $\$ 10,446$ per employee and cover $71 \%$ of a household's premium. ${ }^{57,58}$ These employer premiums are equivalent to a $11.29 \%$ tax on payroll exceeding the first $\$ 2$ million (Table 1, Appendix), extrapolated from Sanders et al. ${ }^{28}$ Therefore, any payroll tax less than $11.29 \%$, our upper bound in the SHIFT interface, would result in savings for employers. A $10 \%$ payroll tax would generate $\$ 436$ billion annually, saving $\$ 100$ billion for employers. Additionally, the substantial cost of managing employee healthcare benefits will be relieved, a factor which we conservatively do not include in our calculations. Although taxes are usually associated with deadweight loss, the replacement of the legal obligation to provide healthcare with a tax that does so at a reduced rate is actually likely to act as an economic stimulus for employers. ${ }^{59}$

The remaining $\$ 337$ billion that would be required could be generated by a 5\% tax on household income exceeding the standard deduction, which would yield $\$ 375$ billion (Appendix). ${ }^{28}$ The $\$ 38$ billion surplus could provide a contribution towards transition costs and/or buffer against unanticipated events. Extrapolating again from Sanders et al., ${ }^{28}$ replacement of the premiums currently paid with a $5 \%$ tax would save households an average of $\$ 2369$ (Appendix). This tax structure redistributes the burden of healthcare costs to provide lower-income households with the greatest relief. ${ }^{23}$ For instance, current Medicaid enrollees will continue to pay few or no income taxes toward healthcare as their household income often falls below the standard tax deduction. In addition, the MAA eliminates deductibles and copayments, which are particularly burdensome for low-income households. Pollin et al. provide a comprehensive analysis of the redistributive impacts among households and businesses. ${ }^{23}$

Improvements in system efficiency, such as reductions in billing tasks, will involve a contraction of the workforce. Although the country will benefit from lower costs, it is estimated that 936,000 administrative positions and 746,600 positions in the healthcare insurance industry will become redundant. ${ }^{23}$ However, detailed transition plans have suggested funding for early retirement options, extensive severance, retraining programs and relocation expenses. ${ }^{23}$ Implementation of such a plan is estimated to cost $\$ 61.5$ billion annually over two years, ${ }^{23}$ a sum which would be recouped within the first year by the healthcare savings estimated here. While multiple avenues for financing the transition are possible, a simple solution could involve setting the household income tax to $6 \%$ for the first two years followed by a stabilization at $5 \%$. 


\section{The life-saving potential of Medicare for All}

Beyond economic considerations, the paramount objective of a healthcare system is to save lives. We projected the life-saving impact that the MAA would achieve through the provision of health insurance for the currently uninsured (Figure 4). From age-specific uninsurance rates ${ }^{54,60}$ and the population within each age class, ${ }^{2}$ we calculated the number of uninsured people in each age class, collectively totaling 37,977,297 Americans. Given that uninsured individuals experience a $40 \%$ elevation in age-specific mortality risk, ${ }^{61}$ we calculated the expected number of deaths in each age cohort if all Americans become insured. We estimated that on an annual basis, universal coverage would save the lives of 68,531 Americans. These are predominantly lives of relatively young people, given that the vast majority of individuals older than 64 years are already covered under Medicare. Adults aged 25 to 35 are disproportionately represented, accounting for over 9 million of the uninsured. Based on the age distribution of these premature deaths that would be averted and their corresponding age-specific life expectancies, we calculated that universal coverage would save 1.73 million life-years annually. If the ACA is repealed in its entirety, as is currently being attempted, it is estimated that 21 million Americans will lose health insurance coverage. ${ }^{4}$ Assuming this population is distributed by age proportional to those who are currently uninsured, elimination of the ACA would result in the loss of 38,557 lives and 980,103 life-years, annually.

Studies evaluating the relationship between insurance status and mortality have been limited by the difficulties of reaching sufficient statistical power and of achieving true prospective randomization. ${ }^{62}$ Therefore, we also present the estimated lives saved by universal health care as a function of the increased mortality risk among the uninsured (Figure 5). Our calculation of the life-saving potential of the MAA is highly conservative in a number of aspects. Additional lives would likely be saved through the improvements in continuity of care facilitated by a single-payer system. Furthermore, this calculation does not incorporate the improvements in survival from fully insuring the 41 million Americans who are currently underinsured, and therefore forego necessary care. ${ }^{1}$

\section{Synergies between health and prosperity}

In addition to averting mortality, substantial morbidity would be alleviated through both the mechanisms of universal coverage and single-payer financing. Universal coverage removes barriers to accessing existing primary and preventative care, and a single-payer system incentivizes the expansion of preventative programs. Preventative care reduces the incidence of myriad diseases, including diabetes, ${ }^{63}$ heart disease ${ }^{64}$ and osteoporosis, ${ }^{65}$ all of which erode quality of life even in cases that do not result in death. For example, prompt diagnosis of prediabetes combined with provider recommendations about diet and exercise can reduce the risk of progressing to diabetes. ${ }^{63}$ Given that a single-payer system would be financially responsible for healthcare throughout the lifespan of all Americans, it becomes efficient to incur a small cost in the present with the purpose of avoiding more serious and costly health conditions in the future. By contrast, private insurance companies, within which patients are most often transiently enrolled, maximize profit by minimizing short-term costs. While this practice reflects the fiduciary responsibility of health insurance 
corporations to their shareholders, it also inherently disincentivizes prioritization of longterm health. Shortsighted cost-cutting can catalyze a cascade of longer-term health and financial repercussions over the lifespan of a patient. The single payer healthcare system in Canada spends more per capita on prevention and allocates over double to prevention as a share of total national health expenditure. ${ }^{66}$ This is especially startling in light of the elevated rates of chronic disease that plague the US. For example, men in the US have a $28 \%$ higher mortality rate from cardiovascular disease compared to Canadian men. ${ }^{67}$

The repercussions of cost-cutting in the US extend beyond chronic diseases. For example, despite the unprecedented epidemic of opioid dependence in the US, many insurance companies continue to refuse reimbursement for less addictive, but more expensive medications, and for physical therapy alternatives. ${ }^{68}$ Over a patient's lifetime, the higher prices of alternative medications for chronic pain are likely to be dwarfed by the benefits to health and quality of life that stem from averting addiction, as well as the downstream costs of substance abuse treatment. Consistent with this quagmire, it is specifically employerbased healthcare insurance, as compared with Medicare, which favors the use of addictive pharmaceuticals for the treatment of pain in lieu of more expensive options, including physical therapy. ${ }^{69}$ Exacerbating the crisis, opioid manufacturers embarked on an aggressive marketing campaign over the last three decades unleashed by the lifting of regulations by the Food and Drug Administration on direct consumer advertising of pharmaceuticals, including narcotics. In addition, opioid manufacturers aggressively targeted the physician training to promote the prescription of opioids and funded advocacy programs that argued that excessively judicious prescription of narcotics had lead to unnecessary suffering of patients. ${ }^{70}$ Consequently, the epidemic of opioid dependence boomed and now exceeds that in any other country. In the single-payer healthcare country of Canada, for example, mortality attributable to opioid overdoses is $32 \%$ lower than that in the US. ${ }^{71}$ The MAA will cover the treatment of drug use disorders, including medication-assisted treatment, behavioral therapies and in-patient care.

Universal health insurance would also lead to positive economic externalities by enhancing workforce productivity. For example, prostate cancer causes $\$ 5.4$ billion in lost productivity among patients, a sum further compounded by the $\$ 3.0$ billion in lost productivity among spouses of these patients. ${ }^{72}$ The productivity loss attributable to diabetes is even greater, as the absenteeism, reduced productivity at work, disability and premature mortality resulting from this condition are annually responsible for $\$ 73.7$ billion in losses across the US. ${ }^{73}$ By extending access to screening and preventive care, the MAA would help avert these diseases and thereby boost American prosperity.

\section{Improving the continuity of healthcare}

Contrary to the popular misconception that a federal healthcare system would restrict provider selection by patients, a single-payer system integrates all providers under a unified financial framework. This restructuring erases in-network and out-of-network distinctions, as well as the issue of providers declining to accept individuals based on their insurance status. Patient choice will in fact be dramatically expanded. With the uncoupling of employment status from insurance plans, a single-payer system would also resolve the 
fragmentation under the current system that arises during employment transition — if, for example, a patient's former doctor is considered out-of-network under a new employer's insurance plan. This fragmentation erodes the efficacy of chronic disease management and delays care for acute conditions. Universal single-payer coverage eliminates the danger of losing healthcare when it is needed most. For many Americans, a serious illness precipitates the simultaneous losses of income and employment-based health insurance. The Americans with Disabilities Act does not protect employees whose medical needs become "burdensome" to their employer, and an extended absence can lead to simultaneous unemployment and loss of health insurance. For example, 19\% of women diagnosed with breast cancer become unemployed within four months following treatment. ${ }^{74}$ Such confluence of unemployment and loss of health insurance gravely impacts health outcomes. Among cancer patients, lacking health insurance is associated with $17 \%$ and $30 \%$ elevation in risks of metastasis and death, respectively. ${ }^{75}$

Fragmentation is particularly problematic in the treatment of chronic diseases, such as mental illness. Currently, 57\% of the 50 million Americans who experience mental illness are not receiving treatment, ${ }^{76,77}$ the most common reason for which is prohibitive cost. ${ }^{78,79}$ Even plans that ostensibly cover mental illness and substance use disorders may nonetheless have low rates of treatment authorization and limited networks of practitioners. ${ }^{79}$

Precariously, abandoning protection for individuals with pre-existing conditions will lead to mounting premiums for people with a history of mental illness or a substance use disorder. By removing cost barriers for patients as well as by consolidating mental health practitioners into a single network, the MAA would help close the perpetually widening gap between mental health needs and access to services.

\section{Time to Act}

As public support for healthcare reform mounts in the US, legislators are poised to transform the healthcare system and save thousands of lives every year. Single-payer universal healthcare has the potential to improve the quality, cost-effectiveness and accessibility of medical services. Our projections indicate that shifting to the MAA specifically would generate net savings across a wide range of possible expenditure and financing options. Objections to MAA based on the expectation of rising cost are therefore mistaken. Some Americans express concern about the federal government controlling this large sector of the economy, or about violating capitalist principles. However, the healthcare sector is already highly regulated in many aspects, and deviates from capitalist ideals through opaque and often monopolistic pricing. Strong opposition should be expected from powerful vested interests, including the health insurance and pharmaceutical industries. Counterbalancing these concerns is the moral imperative to provide healthcare as a human right, not dependent on employment or affluence. We should seize this opportunity to promote wellbeing, enhance prosperity, and establish a more equitable healthcare system for all Americans.

\section{Supplementary Material}

Refer to Web version on PubMed Central for supplementary material. 


\section{Funding Source:}

A.P.G. is supported by the Burnett and Stender Families' Endowment. A.S.P is supported by the Yale Climate Change and Health Initiative through a grant from the Overlook International Foundation. M.C.F is supported by the National Institutes of Health grant K01 AI141576 and the Notsew Orm Sands Foundation.

\section{References:}

1. Collins SR, Gunja MZ, Doty MM. How Well Does Health Coverage Protect Consumers from Costs? Findings from the Commonwealth Fund Biennial Health Insurance Survey, 2016. The Commonwealth Fund, 2017 http://www.commonwealthfund.org/ /media/files/publications/issuebrief/2017/oct/collins_underinsured_biennial_ib.pdf.

2. United States Census Bureau. Annual Estimates of the Resident Population for Selected Age Groups by Sex for the United States, States, Counties, and Puerto Rico Commonwealth and Municipios: April 1, 2010 to July 1, 2017 more information 2017 Population Estimates. American FactFinder. 2018; published online June. https://factfinder.census.gov/bkmk/table/1.0/en/PEP/2017/ PEPAGESEX (accessed July 3, 2018).

3. Auter ZUS Uninsured Rate Steady at $12.2 \%$ in Fourth Quarter of 2017. Gallup. 2018; published online 1 16. https://news.gallup.com/poll/225383/uninsured-rate-steady-fourth-quarter-2017.aspx (accessed July 3, 2018).

4. Fiedler M, Adler L. How will the Graham-Cassidy proposal affect the number of people with health insurance coverage? Brookings. 2017; published online 9 22. https://www.brookings.edu/research/how-will-the-graham-cassidy-proposal-affect-the-numberof-people-with-health-insurance-coverage/ (accessed March 27, 2019).

5. Organisation for Economic Co-operation Development. OECD Health Statistics 2015. OECD. 2015. https://www.oecd-ilibrary.org/social-issues-migration-health/data/oecd-healthstatistics_health-data-en.

6. CMS. NHE Fact Sheet. Centers for Medicare and Medicaid Services. 2018; published online 4 17. https://www.cms.gov/research-statistics-data-and-systems/statistics-trends-and-reports/ nationalhealthexpenddata/nhe-fact-sheet.html (accessed June 8, 2018).

7. GBD 2015 Healthcare Access and Quality Collaborators. Electronic address: cjlm@uw.edu, GBD 2015 Healthcare Access and Quality Collaborators. Healthcare Access and Quality Index based on mortality from causes amenable to personal health care in 195 countries and territories, 19902015: a novel analysis from the Global Burden of Disease Study 2015. Lancet 2017; 390: 231-66. [PubMed: 28528753]

8. Infant Mortality Rate. The World Factbook - Central Intelligence Agency. https://www.cia.gov/ library/publications/the-world-factbook/rankorder/2091rank.html (accessed June 7, 2018).

9. GBD 2015 Maternal Mortality Collaborators. Global, regional, and national levels of maternal mortality, 1990-2015: a systematic analysis for the Global Burden of Disease Study 2015. Lancet. 2016; 388: 1775-812. [PubMed: 27733286]

10. World Health Organization. World Health Statistics 2017: Monitoring Health for the SDGs, Sustainable Development Goals. World Health Organization, 2017.

11. Congressional Budget Office. Preliminary Analysis of Legislation That Would Replace Subsidies for Health Care With Block Grants. Congressional Budget Office, 2017 https://www.cbo.gov/ system/files/115th-congress-2017-2018/costestimate/53126-health.pdf.

12. Sanders B To establish a Medicare-for-all national health insurance program. $2017 \mathrm{https}: / / \mathrm{www}$. sanders.senate.gov/download/medicare-for-all-act?id=6CA2351C-6EAE-4A11BBE4-CE07984813C8\&download=1\&inline=file.

13. Single Payer Healthcare Interactive Financing Tool. http://shift.cidma.us (accessed Feb 21, 2019).

14. McWilliams JM, Meara E, Zaslavsky AM, Ayanian JZ. Health of previously uninsured adults after acquiring Medicare coverage. JAMA 2007; 298: 2886-94. [PubMed: 18159058]

15. Colla CH, Morden NE, Sequist TD, Mainor AJ, Li Z, Rosenthal MB. Payer Type and Low-Value Care: Comparing Choosing Wisely Services across Commercial and Medicare Populations. Health Serv Res 2018; 53: 730-46. [PubMed: 28217968] 
16. Barnett ML, Linder JA, Clark CR, Sommers BD. Low-Value Medical Services in the Safety-Net Population. JAMA Intern Med 2017; 177: 829-37. [PubMed: 28395014]

17. Medicare And Medicaid At 50. The Henry J. Kaiser Family Foundation. 2015; published online 7 17. https://www.kff.org/medicaid/poll-finding/medicare-and-medicaid-at-50/ (accessed Jan 8, 2019).

18. Blahous C The Costs of a National Single-Payer Healthcare System. Mercatus Research Paper 2018; published online 7 30. DOI:10.2139/ssrn.3232864.

19. Friedman G Yes, We Can Have Improved Medicare for All. The Hopbrook Institute, 2018 https://f411bec1-69cf-4acb-bb86-370f4ddb5cba.filesusr.com/ugd/ 698411_9144a6d2d0374ec1a183b30e8369738b.pdf.

20. Thorpe KE. An Analysis of Senator Sanders Single Payer Plan. Emory University, 2016 https://www.healthcare-now.org/296831690-Kenneth-Thorpe-s-analysis-of-Bernie-Sanderss-single-payer-proposal.pdf.

21. Holahan J, Clemans-Cope L, Buettgens M, Favreault M, Blumberg LJ, Ndwandwe S. The Sanders single-payer health care plan. Urban Institute 2016. https://www.researchgate.net/profile/ Linda_Blumberg/publication/303826315_The_Sanders_SinglePayer_Health_Care_Plan_The_Effect_on_National_Health_Expenditures_and_Federal_and_Priva te_Spending/links/5756bb2e08ae5c654903d59b/The-Sanders-Single-Payer-Health-Care-Plan-TheEffect-on-National-Health-Expenditures-and-Federal-and-Private-Spending.pdf.

22. Liu JL, Eibner C. National Health Spending Estimates Under Medicare for All. 2019. https:// www.rand.org/pubs/research_reports/RR3106.html.

23. Pollin R, Heintz J, Arno P, Wicks-Lim J, Ash M. Economic Analysis of Medicare for All. Political Economy Research Institute at the University of Massachusetts Amherst. 2018; published online 11 30. https://www.peri.umass.edu/publication/item/1127-economic-analysis-of-medicarefor-all (accessed Dec 5, 2019).

24. Berwick DM, Johnson S. Medicare for All Cost Letter. Senator Elizabeth Sanders, 2019 https:// assets.ctfassets.net/4ubxbgy9463z/2Tg9oB55ICu2vtYBaKKcVr/ d124e0eeb128ad3a8d8ab8a6ccae44c0/20191031_Medicare_for_All_Cost_Letter__Appendices_ FINAL.pdf\#page $=2$.

25. Frakt AB, Pizer SD, Feldman R. Should Medicare adopt the Veterans Health Administration formulary? Health Econ 2012; 21: 485-95. [PubMed: 21506191]

26. Woolhandler S, Himmelstein DU. Single-Payer Reform: The Only Way to Fulfill the President's Pledge of More Coverage, Better Benefits, and Lower Costs. Ann Intern Med 2017; 166: 587-8. [PubMed: 28241256]

27. Hsiao WC, Knight AG, Kappel S, Done N. What Other States Can Learn From Vermont's Bold Experiment: Embracing A Single-Payer Health Care Financing System. Health Aff 2011; 30: 1232-41.

28. Sanders B Options to Finance Medicare for All. 2017 https://www.sanders.senate.gov/download/ options-to-finance-medicare-for-all?inline=file.

29. Cuckler GA, Sisko AM, Poisal JA, et al. National Health Expenditure Projections, 2017-26: Despite Uncertainty, Fundamentals Primarily Drive Spending Growth. Health Aff 2018; 37: 48292.

30. Hussey PS, Wertheimer S, Mehrotra A. The association between health care quality and cost: a systematic review. Ann Intern Med 2013; 158: 27-34. [PubMed: 23277898]

31. Tsugawa Y, Jha AK, Newhouse JP, Zaslavsky AM, Jena AB. Variation in Physician Spending and Association With Patient Outcomes. JAMA Intern Med 2017; 177: 675-82. [PubMed: 28288254]

32. Hsia RY, Akosa Antwi Y, Weber E. Analysis of variation in charges and prices paid for vaginal and caesarean section births: a cross-sectional study. BMJ Open 2014; 4: e004017.

33. Xu X, Lee HC, Lin H, et al. Hospital variation in cost of childbirth and contributing factors: a cross-sectional study. BJOG 2018; 125: 829-39. [PubMed: 29090498]

34. International Federation of Health Plans. 2015 Comparative Price Report: Variation in Medical and Hospital Prices by Country. iFHP, 2016 https://fortunedotcom.files.wordpress.com/ 2018/04/66c7d-2015comparativepricereport09-09-16.pdf. 
35. OECD. Caesarean sections: OECD Indicators. Health at a Glance 2017. 2017; published online 11 10. DOI:10.1787/health_glance-2017-66-en.

36. Mortality rate, neonatal (per 1,000 live births) | Data. https://data.worldbank.org/indicator/ SH.DYN.NMRT (accessed July 18, 2019).

37. Won RP, Friedlander S, Lee SL. Regional variations in outcomes and cost of appendectomy in the United States. J Surg Res 2017; 219: 319-24. [PubMed: 29078899]

38. Medicare Payment Advisory Commission. Report to the Congress: Medicare Payment Policy. MEDPAC, 2017 http://medpac.gov/docs/default-source/reports/mar17_entirereport.pdf.

39. Coughlin TA. Uncompensated care for the uninsured in 2013: A detailed examination. 2014. https://www.kff.org/uninsured/report/uncompensated-care-for-the-uninsuredin-2013-a-detailed-examination/.

40. Centers for Medicare and Medicaid Services. Historical National Expenditure Accounts. CMS.gov. 2018; published online 1 8. https://www.cms.gov/Research-Statistics-Data-and-Systems/StatisticsTrends-and-Reports/NationalHealthExpendData/NationalHealthAccountsHistorical.html (accessed Aug 13, 2018).

41. American Hospital Association. Uncompensated Hospital Care Cost Fact Sheet. AHA, 2017 https://www.aha.org/system/files/2018-01/2017-uncompensated-care-factsheet.pdf.

42. Sorum P Why Internists Might Want Single-Payer Health Care. Ann Intern Med 2018; 168: 438-9. [PubMed: 29435572]

43. Gundersen L Physician burnout. Ann Intern Med 2001; 135: 145-8. [PubMed: 11453722]

44. Herman B The sky-high pay of health care CEOs. Axios. 2017; published online 7 24. https://www.axios.com/the-sky-high-pay-of-health-care-ceos-1513303956-d5b874a8b4a0-4e74-9087-353a2ef1ba83.html (accessed June 26, 2018).

45. Institute of Medicine. The Healthcare Imperative: Lowering Costs and Improving Outcomes: Workshop Series Summary. Washington, DC: The National Academies Press, 2010.

46. Lu J-FR, Hsiao WC. Does universal health insurance make health care unaffordable? Lessons from Taiwan. Health Aff 2003; 22: 77-88.

47. Reuters. J\&J Raises U.S. Prices on Around Two Dozen Drugs. The New York Times. 2019; published online 1 11. https://www.nytimes.com/reuters/2019/01/10/business/10reuters-johnsonjohnson-drugpricing.html (accessed Jan 11, 2019).

48. Kuchler H Sanofi and Novo Nordisk press ahead with US insulin prices rises. Financial Times. 2019; published online 1 10. https://www.ft.com/content/b102475a-1460-11e9-a581-4ff78404524e (accessed July 29, 2019).

49. Abedi M 'This is a solvable issue': Pricey insulin has Americans trekking to Canada in 'caravans'. Global News. 2019; published online 5 9. https://globalnews.ca/news/5249662/americans-drivingcanada-insulin-prices/ (accessed July 29, 2019).

50. Lakdawalla D, Sood N. Innovation and The Welfare Effects of Public Drug Insurance. J Public Econ 2009; 93: 541-8. [PubMed: 20454467]

51. Arora A, Belenzon S, Patacconi A. Killing the Golden Goose? The Decline of Science in Corporate R\&D. 2015; published online 1. DOI:10.3386/w20902.

52. United States Government Accountability Office. Drug Industry: Profits, Research and Development Spending, and Merger and Acquisition Deals. 2017 https://www.gao.gov/ assets/690/688472.pdf.

53. Brot-Goldberg ZC, Chandra A, Handel BR, Kolstad JT. What does a Deductible Do? The Impact of Cost-Sharing on Health Care Prices, Quantities, and Spending Dynamics. Q J Econ 2017; 132: 1261-318.

54. Berchick ER, Hood E, Barnet JC. Health Insurance Coverage in the United States: 2017. U.S. Department of Commerce Economics and Statistics Administration; U.S. Census Bureau, 2018 https://www.census.gov/content/dam/Census/library/publications/2018/demo/p60-264.pdf.

55. Duron VP, Monaghan SF, Connolly MD, et al. Undiagnosed medical comorbidities in the uninsured: a significant predictor of mortality following trauma. J Trauma Acute Care Surg 2012; 73: 1093-8; discussion 1098-9. [PubMed: 23117376] 
56. Lopez-Gonzalez L, Pickens GT, Washington R, Weiss AJ. Characteristics of Medicaid and Uninsured Hospitalizations, 2012. Healthcare Cost and Utilization Project (HCUP), 2014 https:// www.hcup-us.ahrq.gov/reports/statbriefs/sb182-Medicaid-Uninsured-Hospitalizations-2012.jsp.

57. The Kaiser Family Foundation and Health Research \& Educational Trust. Employer Health Benefits 2017 Summary of Findings. \{Kaiser Family Foundation\}, 2017 http://files.kff.org/ attachment/Summary-of-Findings-Employer-Health-Benefits-2017.

58. US Census Bureau. America's Families and Living Arrangements: 2017, Average number of people (AVG table series). United States Census Bureau. https://www2.census.gov/programssurveys/demo/tables/families/2017/cps-2017/tabavg1.xls (accessed July 18, 2018).

59. Galvani AP, Durham DP, Vermund SH, Fitzpatrick MC. California Universal Health Care Bill: an economic stimulus and life-saving proposal. Lancet 2017; 390: 2012-4. [PubMed: 28923467]

60. Witters D U.S. Uninsured Rate Rises to Four-Year High. Gallup National Health and Well-Being Index. 2019; published online 123 . https://news.gallup.com/poll/246134/uninsured-rate-rises-fouryear-high.aspx (accessed Jan 23, 2019).

61. Wilper AP, Woolhandler S, Lasser KE, McCormick D, Bor DH, Himmelstein DU. Health insurance and mortality in US adults. Am J Public Health 2009; 99: 2289-95. [PubMed: 19762659]

62. Black B, Hollingsworth A, Nunes L, Simon K. The Effect of Health Insurance on Mortality: Power Analysis and What We Can Learn from the Affordable Care Act Coverage Expansions. 2019; published online 2. DOI:10.3386/w25568.

63. Hemmingsen B, Gimenez-Perez G, Mauricio D, Roqué I Figuls M, Metzendorf M-I, Richter B. Diet, physical activity or both for prevention or delay of type 2 diabetes mellitus and its associated complications in people at increased risk of developing type 2 diabetes mellitus. Cochrane Database Syst Rev 2017; 12: CD003054. [PubMed: 29205264]

64. Perk J, De Backer G, Gohlke H, et al. European Guidelines on cardiovascular disease prevention in clinical practice (version 2012). The Fifth Joint Task Force of the European Society of Cardiology and Other Societies on Cardiovascular Disease Prevention in Clinical Practice (constituted by representatives of nine societies and by invited experts). Eur Heart J 2012; 33: 1635-701. [PubMed: 22555213]

65. Nayak S, Roberts MS, Greenspan SL. Cost-effectiveness of different screening strategies for osteoporosis in postmenopausal women. Ann Intern Med 2011; 155: 751-61. [PubMed: 22147714]

66. Gmeinder M, Morgan D, Mueller M. How much do OECD countries spend on prevention? OECD Health Working Papers, 2017 DOI:10.1787/f19e803c-en.

67. Cardiovascular Disease and Diabetes: Policies for Better Health and Quality of Care |READ online. OECD iLibrary. https://read.oecd-ilibrary.org/social-issues-migration-health/cardiovascular-disease-anddiabetes-policies-for-better-health-and-quality-of-care_9789264233010-en (accessed July 2, 2019).

68. Thomas K, Ornstein C. Amid opioid crisis, insurers restrict pricey, less addictive painkillers. NY Times 2017.

69. Amos O Why opioids are such an American problem. BBC. 2017; published online 10 25. https:// www.bbc.com/news/world-us-canada-41701718 (accessed July 19, 2019).

70. Kolodny A, Courtwright DT, Hwang CS, et al. The prescription opioid and heroin crisis: a public health approach to an epidemic of addiction. Annu Rev Public Health 2015; 36: 559-74. [PubMed: 25581144]

71. Priest KC, Gorfinkel L, Klimas J, Jones AA, Fairbairn N, McCarty D. Comparing Canadian and United States opioid agonist therapy policies. Int J Drug Policy 2019; published online 211. DOI:10.1016/j.drugpo.2019.01.020.

72. Rizzo JA, Zyczynski TM, Chen J, Mallow PJ, Trudel GC, Penrod JR. Lost Labor Productivity Costs of Prostate Cancer to Patients and Their Spouses: Evidence From US National Survey Data. J Occup Environ Med 2016; 58: 351-8. [PubMed: 27058474]

73. American Diabetes Association. Economic costs of diabetes in the U.S. in 2012. Diabetes Care 2013; 36: 1033-46. 
74. Blinder V, Eberle C, Patil S, Gany FM, Bradley CJ. Women With Breast Cancer Who Work For Accommodating Employers More Likely To Retain Jobs After Treatment. Health Aff 2017; 36: 274-81.

75. Aizer AA, Falit B, Mendu ML, et al. Cancer-specific outcomes among young adults without health insurance. J Clin Oncol 2014; 32: 2025-30. [PubMed: 24888800]

76. Center for Behavioral Health Statistics and Quality. Behavioral Health Trends in the United States: Results from the 2014 National Survey on Drug Use and Health. Substance Abuse and Mental Health Services Administration (SAMHSA), 2015 https://www.samhsa.gov/data/sites/ default/files/NSDUH-FRR1-2014/NSDUH-FRR1-2014.pdf.

77. National Institute of Mental Health. Mental Illness. National Institute of Mental Health. 2017; published online 11. https://www.nimh.nih.gov/health/statistics/mental-illness.shtml (accessed June 8, 2018).

78. FIrth J, Kirzinger A, Brodie M. Kaiser Health Tracking Poll: April 2016-Substance Abuse and Mental Health. The Henry J Kaiser Family Foundation 2016. https://www.kff.org/report-section/ kaiser-health-tracking-poll-april-2016-substance-abuse-and-mental-health/.

79. National Alliance on Mental Illness (NAMI). A Long Road Ahead: Achieving True Parity in Mental Health and Substance Use Care. NAMI, 2015 https://www.nami.org/About-NAMI/ Publications-Reports/Public-Policy-Reports/A-Long-Road-Ahead/2015-ALongRoadAhead.pdf.

80. Woolhandler S, Himmelstein DU. The Relationship of Health Insurance and Mortality: Is Lack of Insurance Deadly? Ann Intern Med 2017; 167: 424-31. [PubMed: 28655034]

81. Franks P Health insurance and mortality. Evidence from a national cohort. JAMA: The Journal of the American Medical Association. 1993; 270: 737-41. [PubMed: 8336376]

82. Kronick R Health insurance coverage and mortality revisited. Health Serv Res 2009; 44: 1211-31. [PubMed: 19453392]

83. Sommers BD, Long SK, Baicker K. Changes in mortality after Massachusetts health care reform: a quasi-experimental study. Ann Intern Med 2014; 160: 585-93. [PubMed: 24798521]

84. Sommers BD. State Medicaid Expansions and Mortality, Revisited: A Cost-Benefit Analysis. American Journal of Health Economics 2017; 3: 392-421.

85. Sorlie PD, Johnson NJ, Backlund E, Bradham DD. Mortality in the uninsured compared with that in persons with public and private health insurance. Arch Intern Med 1994; 154: 2409-16. [PubMed: 7979836] 


\section{Panel 1:}

Parameter defaults and bounds for the Single-Payer Healthcare Interactive Financing Tool (SHIFT)

\section{Healthcare Budget}

(a) Reducing reimbursement rates for hospitals.: If all hospital fees were reimbursed at current Medicare rates, the fees would overall be 5.54\% lower (default) overall, and if reimbursed at Medicaid rates, fees would be reduced by $18.74 \%$ (upper bound).

(b) Reducing reimbursement rates for physician/clinical services.: If all physician and clinical services were reimbursed at current Medicare rates, the fees would overall be $7.38 \%$ lower (default), and if reimbursed at Medicaid rates, fees would be reduced by $19.23 \%$ (upper bound).

(c) Reducing pharmaceutical prices via negotiation.: The VA has the authority to negotiate prices in accordance with therapeutic value, achieving prices that are $40 \%$ lower than those paid by Medicare 25 (default).

(d) Reducing overhead expenditure.: Within the US system currently, insurance overhead ranges from 2.2\% for Medicare (lower bound, default) to $12.4 \%$ for the private sector $^{26}$ (upper bound).

(e) Improving fraud detection.: Given estimates that $4 \%$ of healthcare expenditure (default) could be eliminated through fraud detection within the first two years of implementing a single-payer system, ${ }^{27}$ we allow fraud reduction to range from $0 \%$ (lower bound) to $10 \%$ (upper bound) upon enactment of the MAA.

\section{Expansion in Utilization}

\section{(f), (g) Utilization of the uninsured and underinsured relative to the adequately insured after enactment of the MAA.}

We allow expected healthcare utilization by un- and under-insured Americans to range from current levels (lower bound) to usage commensurate with those who are fully insured (default, upper bound).

\section{Revenue Generation}

(h) Payroll tax.: The $\$ 536$ billion currently spent by employers on healthcare premiums is equivalent to a $11.29 \%$ payroll tax (upper bound). Any payroll tax that collects revenue below the current expenditure would represent savings, including our default value of $10 \%$.

(i) Household income tax.: Households currently pay $\$ 738$ billion towards premiums and out of pocket expenditures. Only $\$ 64$ billion in out-of-pocket costs would remain under MAA. If the remaining $\$ 674$ billion in spending were replaced by a 5\% household income tax (default) on income beyond the standard deduction, the tax would yield $\$ 375$ billion annually. ${ }^{28}$ The $\$ 674$ billion replaced by MAA would be equivalent to a tax rate of $9 \%$ (upper bound). 
(j) Sanders net worth tax, above \$21 million.: A $1 \%$ tax on household net worth above $\$ 21$ million, applied to $0.1 \%$ of all households, would yield $\$ 109$ billion annually. ${ }^{28}$ This tax rate can be modified by the user to range from $0 \%$ (lower bound, default) to $2 \%$ (upper bound).

See Appendix for additional details on input parameters and assumptions. 


\section{Single-Payer Healthcare Interactive Financing Tool (SHIFT): An Interactive Economic Analysis of the Medicare for All Act (MAA)}
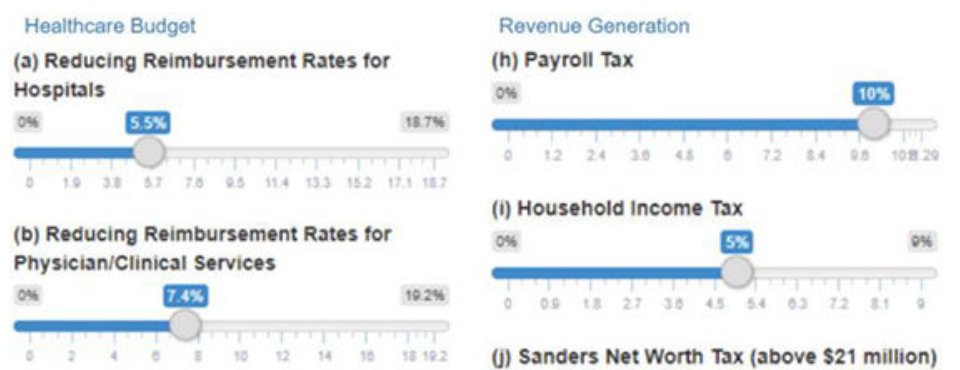

(c) Reducing Pharmaceutical Prices via Negotiation

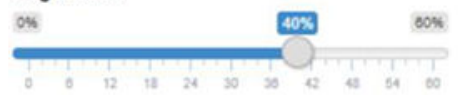

(d) Reducing Overhead Expenditure
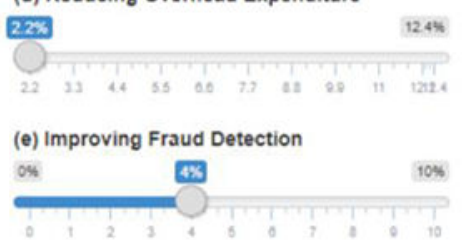

Expansion in Utilization

(f) Utilization by uninsured relative to adequately insured after enactment of MAA

50.16

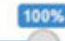

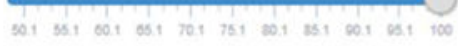

(g) Utilization by underinsured relative to

adequately insured after enactment of MAA

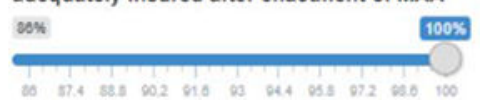

\section{(i) Household Income Tax}

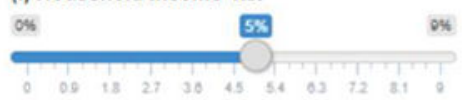

(j) Sanders Net Worth Tax (above \$21 million)

$0 x$

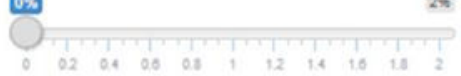

$\square$ Warren net worth tax (above $\$ 50$ million)

Sanders fee on large financial institutions

$\square$ Warren fee on large financial institutions

Reforms to Tax Code

Eliminate accelerated cost recovery

$\square$ Modify the Estate Tax

Eliminate Gingrich-Edwards provision

Eliminate Last-In-First-Out accounting rule

$\square$ Establish minimum for foreign-earning taxes

Eliminate of the Overseas Contingency Operations Fund

Remove preferential rates for capital gains
Additional Tax Options

\section{CIDMA}

The Center for Infectious Disease Modeling and Analysis Yale School of Public Health

Revenue and Budget

4000

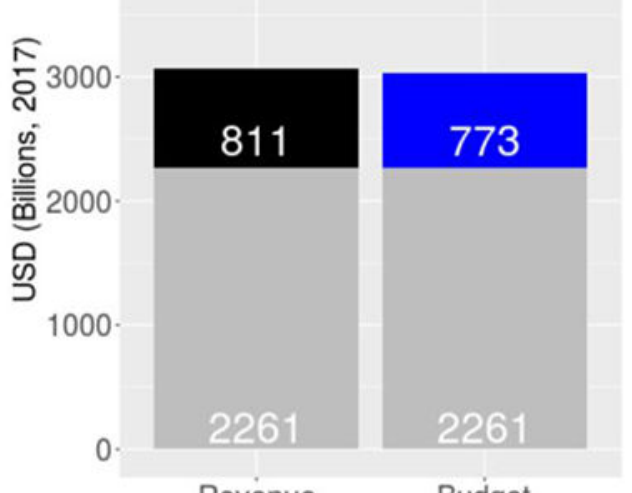

Revenue

Budget

New revenue

New budget

Existing revenue

Regardless of the cost structure selected, the MAA is projected to avert 68,531 deaths and save $1,734,029$ life years on an annual basis.

For details on sources and calculations, see Appendix.

Figure 1. Single-Payer Healthcare Interactive Financing Tool (SHIFT) interface (http:// shift.cidma.us/).

This tool, available at: http://shift.cidma.us/, allows users to adjust input parameters and assumptions, including expansion in utilization, to determine the healthcare budget. The user is also able to select revenue generation options to cover the projected budget. Here, we provide a modified static image of the tool, displaying all adjustable parameters set to their default values. Within the online tool, the Healthcare Budget, Expansion in Utilization and Revenue Generation are individual tabs. Panel 1 details parameter defaults and bounds. 

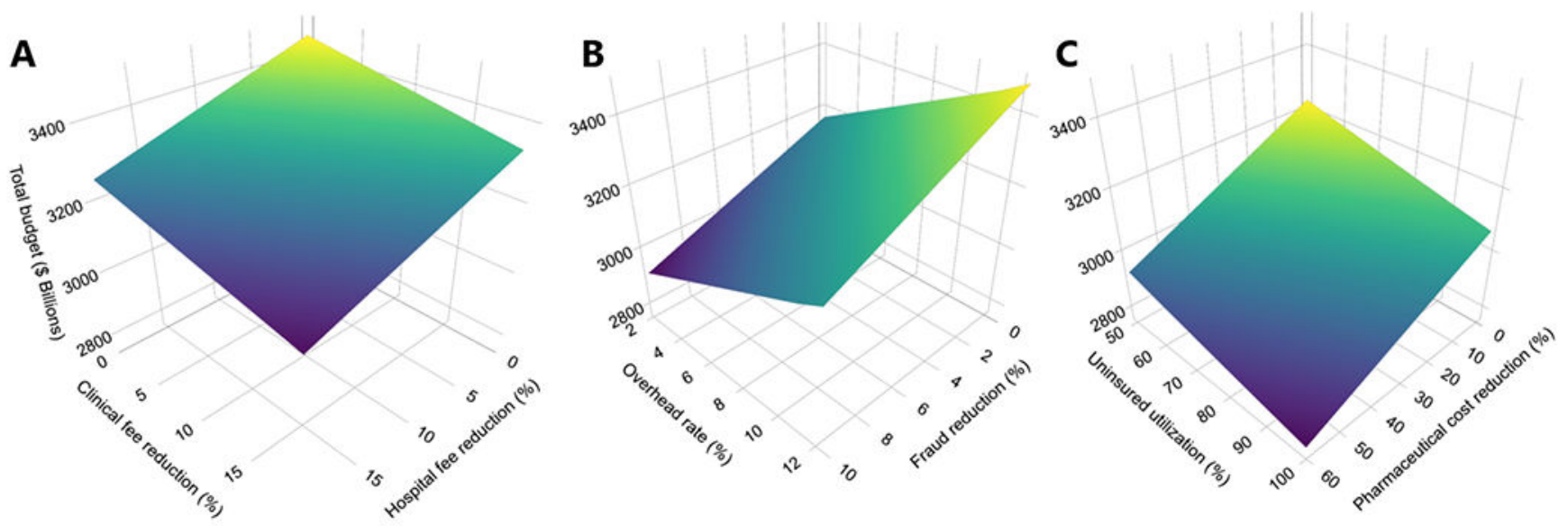

Figure 2. Influence of key parameters on national healthcare expenditure.

(A) Impact of reduction in physician and clinical fees (base case: $7.38 \%$, range: 0 to $19.23 \%$ ) and hospital fees $(5.54 \%, 0$ to $18.74 \%)$ on the total budget. (B) Impact of fraud reduction $(4 \%, 0$ to $10 \%)$ and overhead $(2.2 \%, 2.2$ to $12.4 \%)$ on the total budget. (C) Impact of pharmaceutical price reduction $(40 \%, 0$ to $60 \%)$ and projected healthcare utilization by the uninsured upon becoming insured, compared to those who are already adequately insured $(50.1 \%, 50.1$ to $100 \%)$ on the total budget. For example, if hospital and clinical fees are each reduced by $5 \%$ the total budget becomes $\$ 3054$ billion. Furthermore, the total budget becomes $\$ 3144$ billion if an overhead rate of $2.2 \%$ and a fraud reduction of $0 \%$ are enacted. Lastly, if pharmaceutical costs are reduced by $40 \%$ and healthcare utilization among the uninsured upon becoming insured rises to $50 \%$ of those who are adequately insured, then the total budget would be $\$ 3034$ billion. 


\section{Proposed stepwise changes to healthcare expenditure}

The 2017 federal report of national healthcare spending conducted by the Centers for Medicare and Medicaid Services (CMS) estimated that the country spends the following on healthcare:

Current Expenditure: $\$ 3492$ billion ${ }^{34}$

Consolidating pharmaceutical spending

Given that the MAA would be implemented independently of the Department of Veterans Affairs (VA) and the Indian Health Service (IHS), we separated out the expenditures for these entities from their respective Centers for Medicare and Medicaid Services (CMS) categories. We also consolidated pharmaceutical spending into a single category, including the $\$ 143$ billion in pharmaceuticals that are administered as a component of service provision..$^{53}$ Subtotal: $\$ 3492$ billion

Eliminating uncompensated hospitalization fees

An annual $\$ 38.3$ billion in hospitalization fees are uncollected, equivalent to $3.6 \%$ of the national expenditure for hospital care. ${ }^{39}$ Given that the MAA would reimburse all legitimate healthcare, the national expenditure for hospital services would increase commensurately.

Subtotal: $\$ 3530$ billion

Eliminating avoidable emergency room visits and hospitalizations

Avoidable emergency room visits and hospitalizations can be averted through improved access to primary care. It has been estimated that by providing primary care to people who are currently uninsured, $\$ 7.81$ billion in emergency room expenses ${ }^{59}$ and $\$ 70.4$ billion in hospitalization costs, ${ }^{23}$ together totalling $\$ 78.21$ billion, could be saved.

Subtotal: $\$ 3452$ billion

Reducing reimbursement rates for hospitals, physician/clinical services

The MAA is expected to establish reimbursement rates for hospital fees comparable to those currently paid by Medicare, which are $22 \%{ }^{32}$ lower than private insurance but $30 \%$ higher than Medicaid. ${ }^{32,60}$ Medicare reimbursements for physician and clinical services are $22 \%$ lower than those for private insurance, ${ }^{32}$ but $20 \%$ higher than those for Medicaid.

Subtotal: $\$ 3352$ billion

Reducing pharmaceutical prices via negotiation

Negotiating pharmaceutical prices through the approach used by the VA will allow for a $40 \%$ reduction in prices compared to those currently paid by Medicare.

Subtotal: \$3164 billion

Reducing overhead expenditure

Insurance overhead currently is $2.2 \%$ under Medicare but $12.4 \%$ in the private sector, thus expanding to universal Medicare enrollment will result in a $\$ 226$ reduction in overhead. Subtotal: $\$ 2945$ billion

Improving fraud detection

Through a single-payer system, it is estimated that $4 \%$ of healthcare expenditure

could be eliminated through fraud detection

Subtotal: $\$ 2843$ billion

Insurance expansion

Healthcare spending among uninsured people is $50.1 \%$ of that among their insured counterparts, ${ }^{33}$ while spending among underinsured people is approximately $86.0 \%$ of that spent by those who are adequately insured..$^{43}$

Proposed Expenditure: $\$ 3034$ billion

Figure 3: Overview of Single-Payer Healthcare Interactive Financing Tool Calculations.

Arrows indicate changes in total National Healthcare Expenditure upon implementation of each step. Subtotals and changes in National Healthcare Expenditure have been rounded to the nearest billion. Additional details on steps in the enactment of the MAA and relevant calculations are provided in the Appendix and Appendix Tables. 
Age-specific rates of being uninsured
Age-specific

population

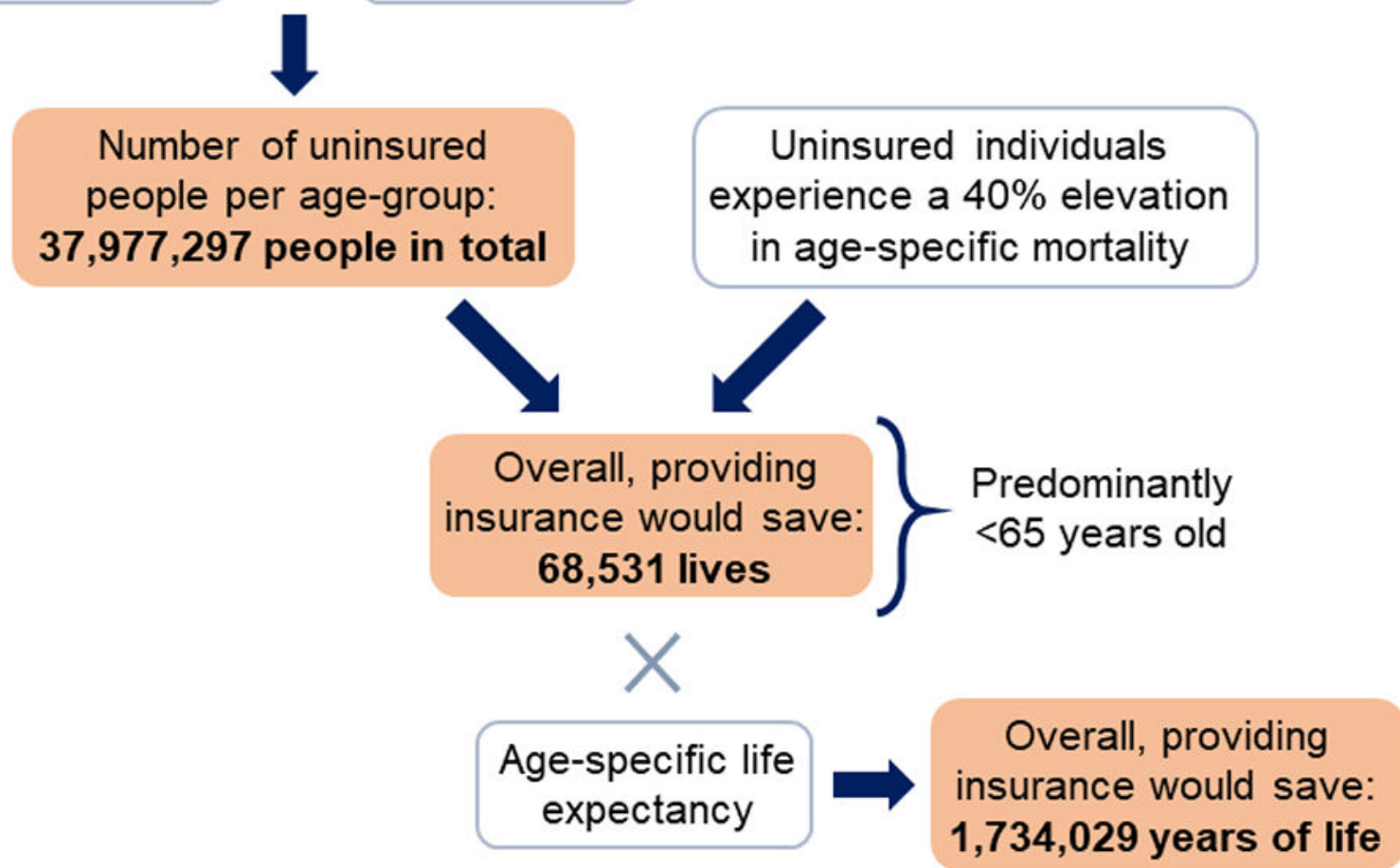

Figure 4:

The life-saving potential of Medicare for All compared to the present. 


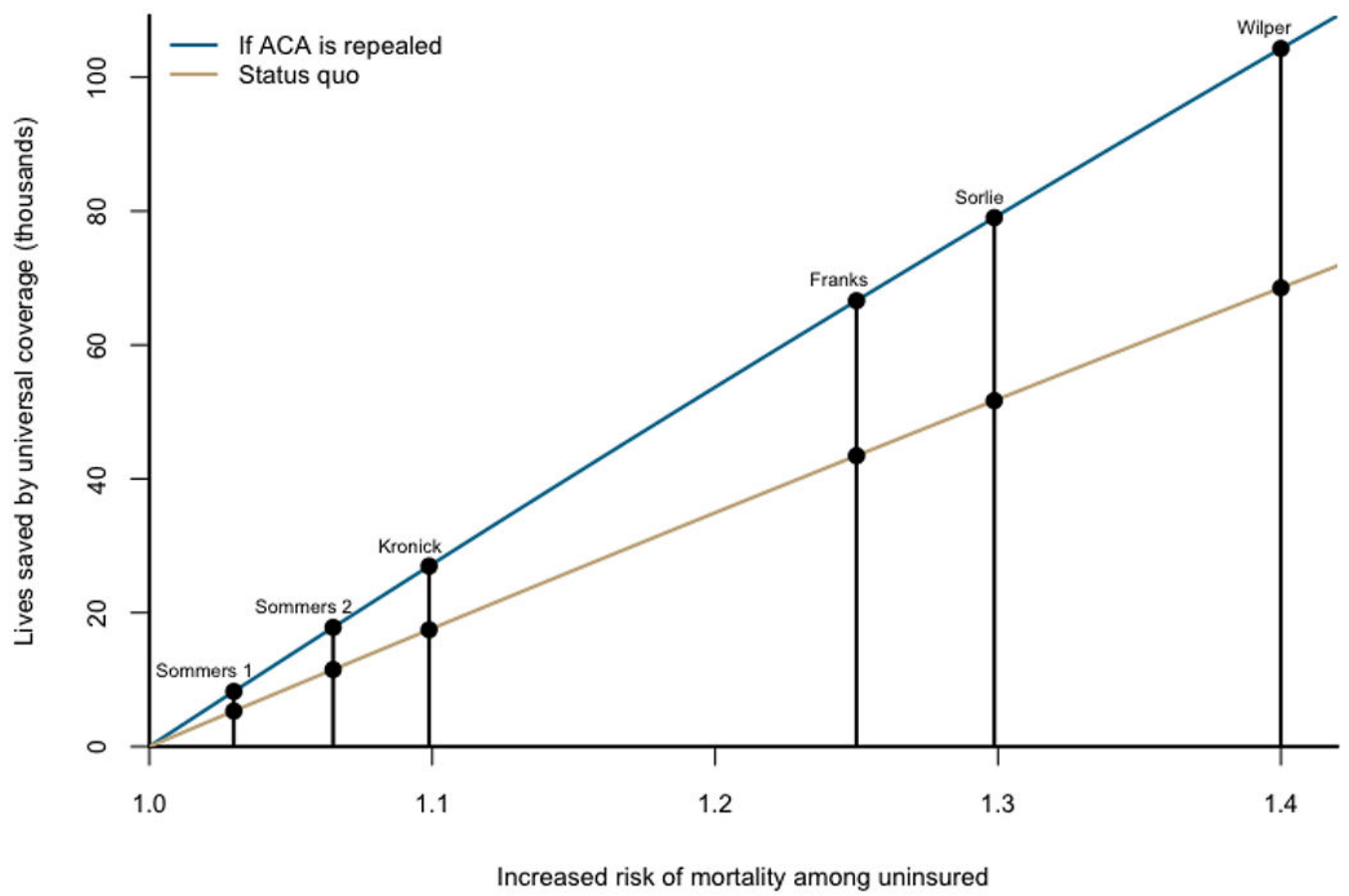

Figure 5:

Lives saved by Medicare for All as a function of increased mortality among the uninsured. The number of uninsured Americans, and therefore the estimated lives saved, would be higher if the Affordable Care Act is repealed (blue line), compared to the current status quo (tan line). Vertical lines indicate studies which found a statistically significant relationship between insurance status and mortality, among those identified in a recent review: 80 Franks, ${ }^{81}$ Kronick, ${ }^{82}$ Sommers $1,{ }^{83}$ Sommers $2,{ }^{84}$ Sorlie, ${ }^{85}$ and Wilper. ${ }^{61}$ 
Table 1:

Employer and household expenditures on healthcare premiums compared with proposed payroll and household taxes, respectively. These expenditures and tax rates derive from Sanders et al. and the Centers for Medicare and Medicaid Services (CMS), ${ }^{28,40}$ as are detailed in the Appendix. For households, the tax rate is applied to income above $\$ 29,000$, as stipulated in Sanders et al. ${ }^{28,40}$

\begin{tabular}{|l|l|l|l|l|}
\hline \multirow{2}{*}{} & \multicolumn{3}{|l|}{ Employer Premiums, National Total } & Household Premiums and Out-of-Pocket Spending, Average \\
\cline { 2 - 5 } & Current & Proposed & Current & Proposed \\
\hline Annual expenditure & $\$ 536$ billion & $\$ 436$ billion & $\$ 5847$ & $\$ 3478$ \\
\hline Equivalent tax rate & $11.29 \%$ & $10 \%$ & $9 \%$ & $5 \%$ \\
\hline
\end{tabular}

